American Journal of Applied Sciences 7 (5): 675-681, 2010

ISSN 1546-9239

(C) 2010Science Publications

\title{
Waste Heat Recovery by Heat Pipe Air-Preheater to Energy Thrift from the Furnace in a Hot Forging Process
}

\author{
${ }^{1}$ Lerchai Yodrak, ${ }^{1}$ Sampan Rittidech, ${ }^{1}$ Nattapol Poomsa-ad and ${ }^{2}$ Pattanapol Meena \\ ${ }^{1}$ Heat-Pipe and Thermal Tools Design Research Lab, \\ Department of Mechanical Engineering, Faculty of Engineering, \\ ${ }^{2}$ Department of Physic, Faculty of Science, \\ Mahasarakham University, Thailand, 44150
}

\begin{abstract}
Problem statement: Currently, the heat pipe air-preheater has become importance equipment for energy recovery from industrial waste heat because of its low investment cost and high thermal conductivity. Approach: This purpose of the study was to design, construct and test the waste heat recovery by heat pipe air-preheater from the furnace in a hot brass forging process. The mathematical model was developed to predict heat transfer rate and applied to compute the heat pipe air-preheater in a hot brass forging process. The heat pipe air-preheater was designed, constructed and tested under medium temperature operating conditions with inlet hot gas ranging between $370-420^{\circ} \mathrm{C}$ using water as the working fluid with $50 \%$ filling by volume of evaporator length. Results: The experiment findings indicated that when the hot gas temperature increased, the heat transfer rate also increased. If the internal diameter increased, the heat transfer rate increased and when the tube arrangement changed from inline to staggered arrangement, the heat transfer rate increased. Conclusion/Recommendations: The heat pipe air-preheater can reduced the quantity of using gas in the furnace and achieve energy thrift effectively.
\end{abstract}

Key words: Heat pipe air-preheater, energy thrift, forging process

\section{INTRODUCTION}

A simple heat pipe consists of a closed container that contains only a working fluid, liquid part and vapor part. Heat is transferred along the tube by a process of boiling, vapor flow, condensation and returned condensate. The vapor travels at high speed to a condenser section of the container, where the heat is rejected during condensation from the returned condensate by gravity. The heat pipe has very good thermal respond because of very high thermal conductance, heat pipes operate almost isothermally with a small temperature difference between the upper and lower end (Payakaruk et al., 2000; Engineering Data Science Unit No. 80017, 1980).

The previous research on the heat pipe, such as; Lukitobudi et al. (1995) studied the application of airto-air heat exchanger for medium temperature heat recovery in bakeries. Noie-Baghban and Majideian (2000) studied waste heat recovery using Heat Pipe Heat Exchanger (HPHE) for surgery rooms in hospital. Nuntaphan and Kiatsiriroat, (2004) modified radiators to be heat pipe and they used as waste heat recovery devices. Wangnipparnto et al. (2003) studied the performance of a thermosyphon heat exchanger at normal temperature under an electric field, using water and R134a as working fluids, having a 6×7 inline arrangement. Wu et al. (1997) studied the application of heat pipe exchangers for humidity control in an air conditioning system. Zukauskas (1987) established a correlation to predict heat transfer from tubes in cross flow.

However, the research did not study on the waste heat recovery in a hot brass forging process by the heat pipe air-preheater. Therefore, the aim this research work is to construct mathematical model for predicting heat transfer rate of the heat pipe air-preheater for waste heat recovery from the furnace in a hot brass forging process and then compared with experimental results.

Figure 1 shows the procedure in a hot brass forging process. In this process, the brass bars were fed into the furnace. The air was heated by flue combustion. Then the hot gas moved through the layer of products. The heat was transferred to the brass bars and waste heat occurred. Afterwards, brass bars were moved to forge.

Corresponding Author: Lerchai Yodrak, Heat-Pipe and Thermal Tools Design Research Lab,

Department of Mechanical Engineering, Faculty of Engineering, Mahasarakham University, Thailand 44150 Tel/Fax: +66 43754316 


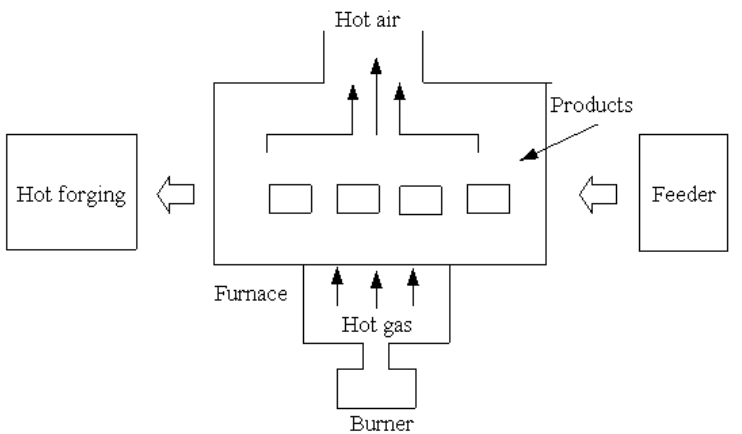

Fig. 1: A hot brass forging process

\section{MATERIALS AND METHODS}

The experimental setup: The heat pipe air-preheater for the forging process divides into 3 parts, i.e., the length of evaporator, adiabatic and condenser sections of $0.15,0.05$ and $0.15 \mathrm{~m}$ respectively. The tube arrangements were staggered and inline in the direction of hot gas flow. The prototype had a duct size area $0.28 \times 0.24 \mathrm{~m}$ covered by fiber insulation.

Figure 2 showing the experimental setup, composing of the heat pipe air-preheater, using water as working fluid with internal diameters of steel tube of 0.013 and $0.020 \mathrm{~m}$. The numbers of tube row were eight rows in each row six tubes. The condenser section was connected to the fresh air section from blower and the evaporator section was connected to with the heat source from the gas burner. The hot gas coming from the gas burner flowed through the heat pipe airpreheater. Fourteen K-type thermocouples (Omega with $\pm 1^{\circ} \mathrm{C}$ accuracy) were installed on the evaporator and condenser sections to monitor the temperatures. The mass flow rate of fresh air and hot gas were measured by a pitot tube (Testo 445 with $\pm 0.1 \mathrm{~m} \mathrm{sec}^{-1}$ accuracy) and set up in the inlet and outlet of the evaporator and the condenser sections. When a steady state was achieved, the temperature at the inlet and outlet of the evaporator and the condenser sections were recorded by a data logger (Yokogawa DX200 with $\pm 0.1^{\circ} \mathrm{C}$ accuracy, 20 channel input and -200 to $1100^{\circ} \mathrm{C}$ measurement temperature rang). The value used to calculate the heat transfer rate of the heat pipe air-preheater is calculated as follows:

$$
\begin{aligned}
& \mathrm{Q}_{\mathrm{e}}=\dot{\mathrm{m}}_{\mathrm{e}}\left(\mathrm{T}_{\text {out }}-\mathrm{T}_{\text {in }}\right) \\
& \mathrm{Q}_{\mathrm{c}}=\dot{\mathrm{m}}_{\mathrm{c}}\left(\mathrm{T}_{\text {out }}-\mathrm{T}_{\text {in }}\right)
\end{aligned}
$$

When:

$$
\mathrm{Q}=\mathrm{f}\left(\dot{\mathrm{m}}, \mathrm{T}_{\text {out }}, \mathrm{T}_{\text {in }}\right)
$$
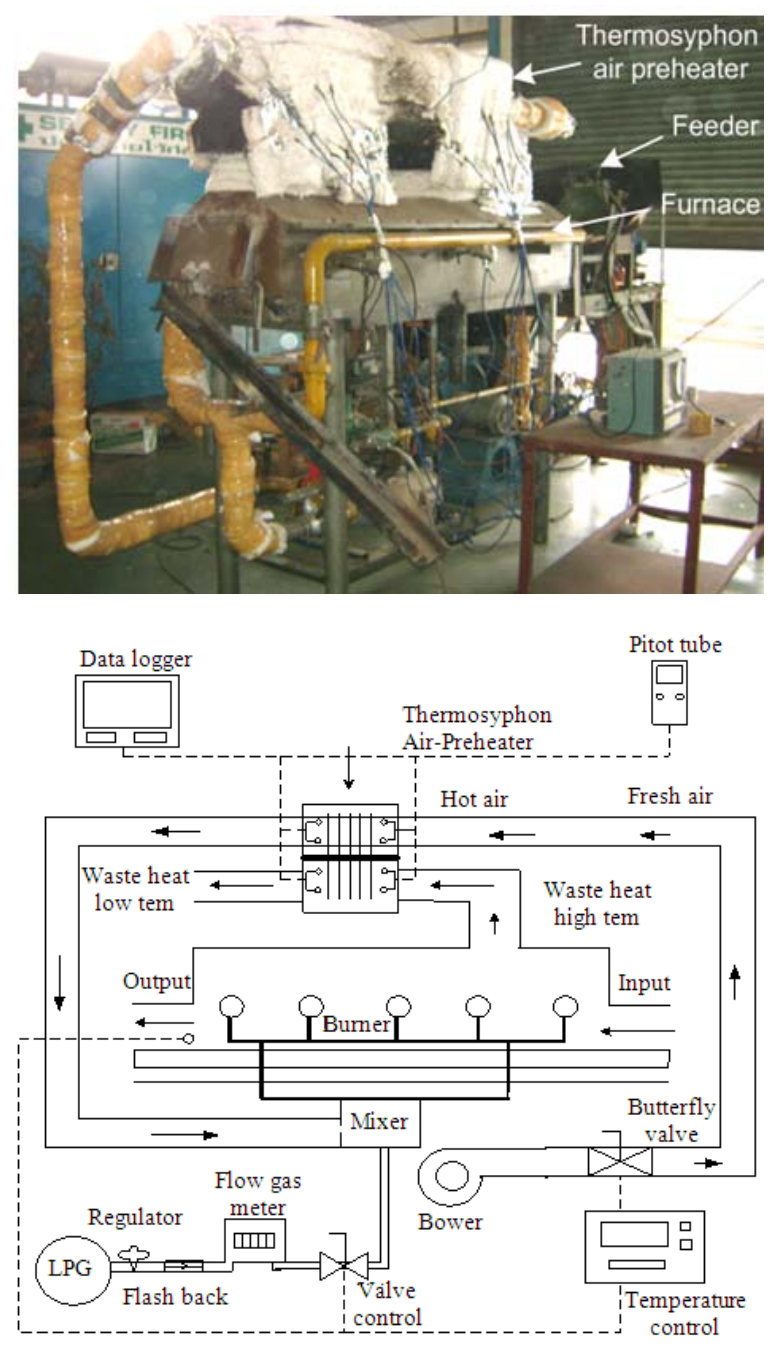

Fig. 2: Experimental set up

And error analysis of heat transfer to obtain:

$\mathrm{WQ}=\left[\begin{array}{l}\left(\frac{\partial \mathrm{Q}}{\partial \dot{\mathrm{m}}} \mathrm{W} \dot{\mathrm{m}}\right)^{2}+\left(\frac{\partial \mathrm{Q}}{\partial \mathrm{T}_{\text {out }}} \mathrm{WT}_{\text {out }}\right)^{2} \\ +\left(\frac{\partial \mathrm{Q}}{\partial \mathrm{T}_{\text {in }}} \mathrm{WT}_{\text {in }}\right)^{2}\end{array}\right]^{\frac{1}{2}}$

Note that Eq. 1 and 2 denote heat transfer rates in the air side of evaporator and condenser sections, respectively. In this study, the mathematical average of the heat transfer rate is used, i.e.:

$\mathrm{Q}_{\mathrm{avg}}=0.5\left(\mathrm{Q}_{\mathrm{e}}+\mathrm{Q}_{\mathrm{c}}\right)$ 

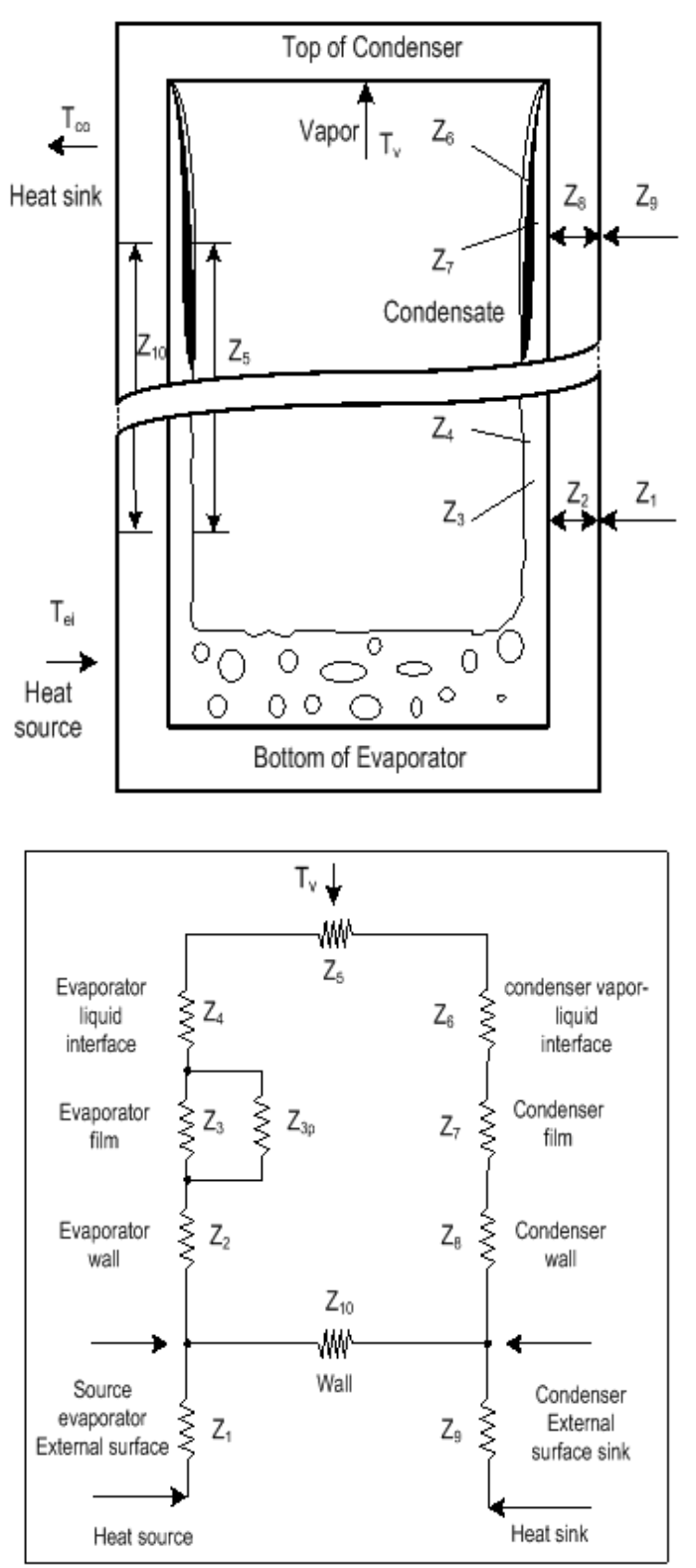

Fig. 3: The thermal resistance circuit of heat pipe

The controlled parameters were: Water working fluid, filling ratio of $50 \%$ by volume (Le) and the inlet temperature of fresh air $\left(40^{\circ} \mathrm{C}\right)$. The variable parameters were: Tube internal diameters of 0.013 and $0.020 \mathrm{~m}$ and the temperatures of hot gas of 370,390 and $420^{\circ} \mathrm{C}$.

Note that, all of the experimental data was collected under the steady state condition and they are used for calculating the heat transfer rates when compared with the predict values.
Data reduction: In this research work, the pressure drops from the evaporator to condenser and the axial conduction along the pipe wall are assumed to be negligible. Figure 3 shows thermal resistance circuit of the heat pipe. The external thermal resistances of the evaporator $\left(Z_{1}\right)$ and condenser surface are $\left(Z_{9}\right)$ as:

$$
\begin{aligned}
& \mathrm{Z}_{1}=\frac{1}{\mathrm{~h}_{\text {ео }} \mathrm{A}_{\text {ео }}} \\
& \mathrm{Z}_{9}=\frac{1}{\mathrm{~h}_{\mathrm{co}} \mathrm{A}_{\text {со }}}
\end{aligned}
$$

For the flue gas side, Hewitt et al. (1994) is adapted for evaluating the heat transfer coefficient $\left(\mathrm{h}_{0}\right)$ calculate as:

$\mathrm{h}_{\mathrm{o}}=\frac{\mathrm{N}_{\mathrm{u}} \mathrm{k}}{\mathrm{D}_{\mathrm{o}}}$

The correlations presented by Zukauskas (1987) are used. Note that the Nusselt number is a function of Reynolds number which based on the tube diameter. For inline and staggered arrangements in the case of number of tube row $\left(N_{r} \geq 16\right)$, the Zukauskas (1987) correlations are:

Staggered:

$$
\overline{\mathrm{N}_{\mathrm{u}}}=0.35\left(\frac{\mathrm{S}_{\mathrm{t}}}{\mathrm{S}_{\mathrm{l}}}\right)^{0.2} \mathrm{R}_{\mathrm{e}}^{0.6} \mathrm{P}_{\mathrm{r}}^{0.36} \quad\left(10^{3}<\mathrm{Re}<2 \times 10^{5}\right)
$$

Inline:

$$
\overline{\mathrm{N}_{\mathrm{u}}}=0.27 \mathrm{R}_{\mathrm{e}}^{0.63} \mathrm{P}_{\mathrm{r}}^{0.36} \quad\left(10^{3}<\mathrm{Re}<2 \times 10^{5}\right)
$$

In the case of the number of tube row less than 16 rows:

$\left.\mathrm{N}_{\mathrm{u}}\right|_{\mathrm{Nr}<16}=\left.\overline{\mathrm{F}} \overline{\mathrm{u}}\right|_{\mathrm{Nr} \geq 16}$

Note that the factor $\mathrm{F}$ was tabulated follow number of tube rows on Table 1. Note that Reynolds number and Prandtl number in this work are defined as:

$$
\begin{aligned}
& \mathrm{R}_{\mathrm{e}}=\frac{\rho \mathrm{V}_{\max } \mathrm{D}_{\mathrm{f}}}{\mu} \\
& \mathrm{P}_{\mathrm{r}}=\frac{\mathrm{C}_{\mathrm{p}} \mu}{\mathrm{k}}
\end{aligned}
$$


Am. J. Applied Sci., 7 (5): 675-681, 2010

Table 1: The correlation coefficients of $\mathrm{F}$

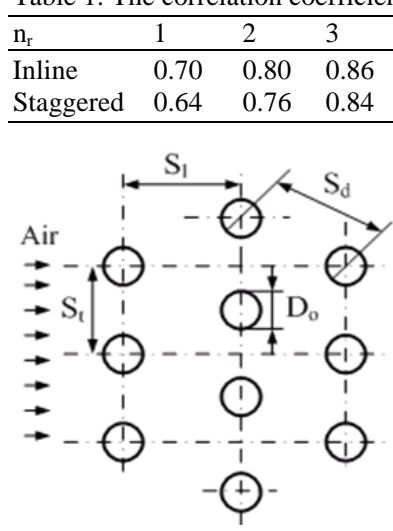

(a)

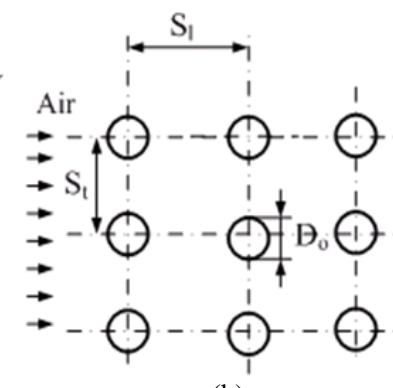

(b)
Fig. 4: Relevant definitions of the geometrical parameters for heat pipe. (a) Inline arrangement; (b) staggered arrangement

Figure 4 shows relevant definitions of the geometrical parameters for heat pipe. The maximum velocities: Of the air inlet are defined as:

Inline:

$\mathrm{V}_{\max }=\left[\frac{\mathrm{S}_{\mathrm{t}}}{\mathrm{S}_{\mathrm{t}}-\mathrm{D}}\right] \mathrm{V}$

Staggered:

$\mathrm{V}_{\text {max }}=2\left[\frac{\mathrm{S}_{\mathrm{t}}}{\mathrm{S}_{\mathrm{d}}-\mathrm{D}}\right] \mathrm{V}$

The wall resistances of evaporator $Z_{2}$ and condenser surface $\mathrm{Z}_{8}$ as:

$\mathrm{Z}_{2}=\frac{\ln \left(\mathrm{D}_{\mathrm{o}} / \mathrm{D}_{\mathrm{i}}\right)}{2 \pi \mathrm{L}_{\mathrm{e}} \mathrm{k}}$

$\mathrm{Z}_{8}=\frac{\ln \left(\mathrm{D}_{\mathrm{o}} / \mathrm{D}_{\mathrm{i}}\right)}{2 \pi \mathrm{L}_{\mathrm{c}} \mathrm{k}}$

$\mathrm{Z}_{3}$ and $\mathrm{Z}_{7}$ are the internal resistances due to pool and film boiling of the working fluids which are divided into $Z_{3 p}$ i.e., resistance from pool boiling and $\mathrm{Z}_{3 \mathrm{f}}$ i.e., resistance from film boiling in the evaporator section:

$$
\begin{aligned}
& \mathrm{Z}_{3 \mathrm{p}}=\frac{1}{\left.\phi_{1} \mathrm{~g}^{0.2} \mathrm{Q}^{0.4}(\pi \mathrm{DL})_{\mathrm{e}}\right)^{0.6}} \\
& \mathrm{Z}_{3 \mathrm{f}}=\frac{0.235 \mathrm{Q}^{1 / 3}}{\mathrm{D}_{\mathrm{i}}^{4 / 3} \mathrm{~g}^{1 / 3} \mathrm{~L}_{\mathrm{e}} \phi_{2}^{4 / 3}}
\end{aligned}
$$

Where:

$$
\begin{aligned}
& \phi_{1}=\frac{\rho_{1}^{0.65} \mathrm{k}_{1}^{0.3} \mathrm{C}_{\mathrm{p}, 1}^{0.7}}{\rho_{\mathrm{v}}^{0.25} \lambda^{0.4} \mu_{1}^{0.1}}\left[\frac{\mathrm{P}_{\mathrm{v}}}{\mathrm{P}_{\mathrm{a}}}\right]^{0.23} \\
& \phi_{2}=\left(\frac{\lambda \mathrm{k}_{1}^{3} \rho_{1}^{2}}{\mu_{\mathrm{l}}}\right)^{0.25}
\end{aligned}
$$

The resistance from film boiling of the working fluid in the condenser section is:

$$
\mathrm{Z}_{7}=\frac{0.235 \mathrm{Q}^{1 / 3}}{\mathrm{D}_{\mathrm{i}}^{4 / 3} \mathrm{~g}^{1 / 3} \mathrm{~L}_{\mathrm{c}} \phi_{2}^{4 / 3}}
$$

$\mathrm{Z}_{4}$ and $\mathrm{Z}_{6}$ are the thermal resistances that occur at the vapor liquid interface in the evaporator and the condenser respectively. $Z_{5}$ is the effective thermal resistance due to the pressure drop of the vapor as it flows from the evaporative to the condenser and $Z_{10}$ is the axial thermal resistance of the wall of the container. These are always neglected, being exceedingly small. The overall thermal resistance is approximated or estimated by:

$\mathrm{Z}_{\text {total }}=\mathrm{Z}_{1}+\mathrm{Z}_{2}+\mathrm{Z}_{3}+\mathrm{Z}_{7}+\mathrm{Z}_{8}+\mathrm{Z}_{9}$

The overall heat transfer coefficient area of the heat pipe air-preheater can be evaluated in the term of thermal resistance as:

$\mathrm{UA}_{\text {total }}=\frac{1}{\left(\mathrm{Z}_{1}+\mathrm{Z}_{2}+\mathrm{Z}_{3}+\mathrm{Z}_{7}+\mathrm{Z}_{8}+\mathrm{Z}_{9}\right)}$

The overall heat transfer rate of the heat pipe airpreheater for parallel flow arrangement can be calculated by:

$\mathrm{Q}=\mathrm{UA} \Delta_{\text {lmtd }}$

Where:

$$
\Delta_{\text {lmtd }}=\frac{\left(\mathrm{T}_{\mathrm{hi}}-\mathrm{T}_{\mathrm{ci}}\right)-\left(\mathrm{T}_{\mathrm{ho}}-\mathrm{T}_{\mathrm{co}}\right)}{\ln \left(\frac{\mathrm{T}_{\mathrm{hi}}-\mathrm{T}_{\mathrm{ci}}}{\mathrm{T}_{\mathrm{ho}}-\mathrm{T}_{\mathrm{co}}}\right)}
$$

Where:

$$
\begin{aligned}
\mathrm{A} & =\text { Area }\left(\mathrm{m}^{2}\right) \\
\mathrm{D} & =\operatorname{Diameter}(\mathrm{m}) \\
\mathrm{F} & =\text { Empirical constants } \\
\mathrm{h} & =\text { Heat transfer coefficient }\left(\mathrm{W} \mathrm{m}^{-2} \mathrm{~K}\right) \\
\mathrm{k} & =\text { Thermal conductivity }\left(\mathrm{W} \mathrm{m}{ }^{-2} \mathrm{~K}\right) \\
\mathrm{L} & =\text { Length }(\mathrm{m}) \\
\dot{\mathrm{m}} & =\text { Mass flow rate }\left(\mathrm{kg} \mathrm{sec}^{-1}\right)
\end{aligned}
$$


$\mathrm{n} \quad$ = Number of tube bank

$\mathrm{Q} \quad=$ Heat transfer rate $(\mathrm{W})$

$\mathrm{S}_{1} \quad$ = Longitudinal pit of tube bank (m)

$\mathrm{S}_{\mathrm{t}} \quad=$ Transverse pith of tube bank (m)

$\mathrm{S}_{\mathrm{d}}=$ Diagonal pith of tube bank (m)

$\Delta_{\text {lmtd }}=$ Log mean temperature difference $\left({ }^{\circ} \mathrm{C}\right)$

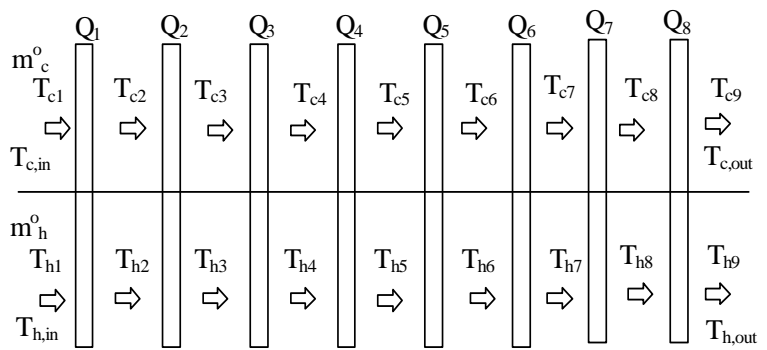

(a)

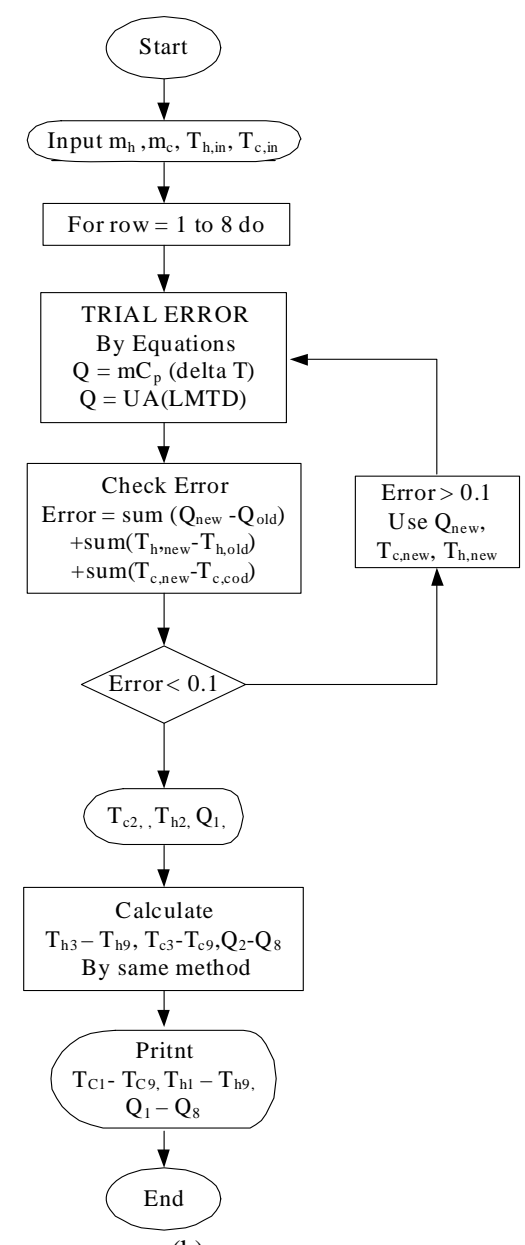

(b)

Fig. 5: Flow chart for calculating the heat transfer rates of the parallel flow the heat pipe air-preheater
Mathematical models: The mathematical model of this study is analogous to that of Wangnipparnto et al. (2003). Note that Wangnipparnto et al. (2003) program is valid for the simulation at normal temperature condition $\left(90-150^{\circ} \mathrm{C}\right)$. While the present simulation program develops for predicting at medium temperature condition $\left(370-420^{\circ} \mathrm{C}\right)$ and applies to compute the heat pipe air-preheater in a hot brass forging process. Figure 5 shows the flow chart of the calculation method. First we feed input all of working conditions and dimension of heat pipe air-preheater. Second we assume values of inlet and outlet temperatures and the heat transfer rate of each row. Third we re-calculate until all the computational values do not change. Fourth we start with row 2 by the same method until the last row is carried out.

\section{RESULTS}

Effect of hot gas temperature on heat transfer rate: In the case of inline arrangement, the effect was measured for the heat pipe air-preheater with eight rows and six columns when the internal diameter of $0.020 \mathrm{~m}$ with the mass flow rates of 0.0092 and $0.0098 \mathrm{~kg} \mathrm{sec}^{-1}$. Figure 6 compares the hot gas temperature with the heat transfer rate. When the hot gas temperature increased from $370-420^{\circ} \mathrm{C}$, the heat transfer rate also increased from 1649.1-1996.6 W. For staggered arrangement, the effect was measured for the heat pipe air-preheater with eight rows and six columns when internal diameter of $0.020 \mathrm{~m}$ with the mass flow rates of 0.0092 and $0.0098 \mathrm{~kg} \mathrm{sec}^{-1}$. Figure 7 compares the hot gas temperature with the heat transfer rate. When the hot gas temperature increased from $370-420^{\circ} \mathrm{C}$, the heat transfer rate also increased from 1771.8-2273.6 W. For both arrangements, the experimental results of the heat transfer rate were similar. The highest heat transfer was attained at the maximum temperature of $420^{\circ} \mathrm{C}$. This is because when the hot gas inlet temperature increased, the hot gas outlet air temperature also increased. Thus, the temperature difference between the inlet and outlet hot gas increased and the heat transfer rate was high.

Effect of internal diameter on heat transfer rate: In the case of inline arrangement, the effect was measured for the heat pipe air-preheater with eight rows and six columns, when the hot gas temperature was $420^{\circ} \mathrm{C}$ and the mass flow rate of $0.0098 \mathrm{~kg} \mathrm{sec}{ }^{-1}$. Figure 6 compares the internal diameter with the heat transfer rate. When the internal diameter changed from $0.013-$ $0.020 \mathrm{~m}$, the heat transfer rate increased from 1884.81996.6 W. For staggered arrangement, the effect was measured for the heat pipe air-preheater with eight rows and six columns, when the hot gas temperature was $420^{\circ} \mathrm{C}$ and mass flow rate of $0.0098 \mathrm{~kg} \mathrm{sec}^{-1}$. 
Am. J. Applied Sci., 7 (5): 675-681, 2010

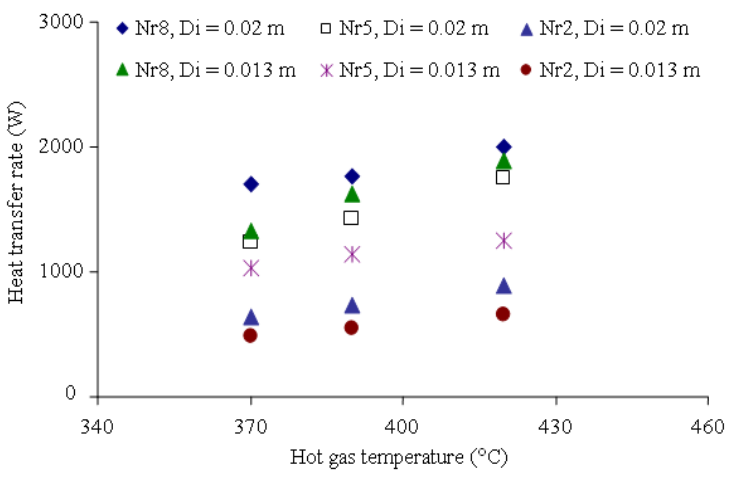

Fig. 6: The effect of hot gas temperature and internal diameter on heat transfer in the case of inline arrangement

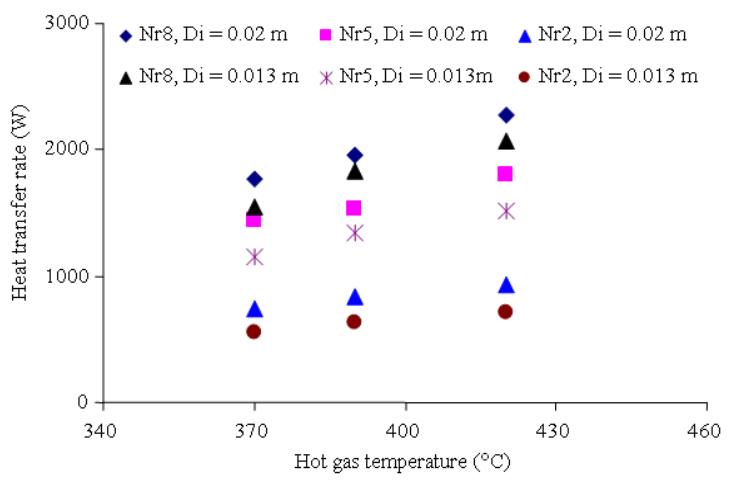

Fig. 7: The effect of hot gas temperature and internal diameter on heat transfer in the case of staggered arrangement

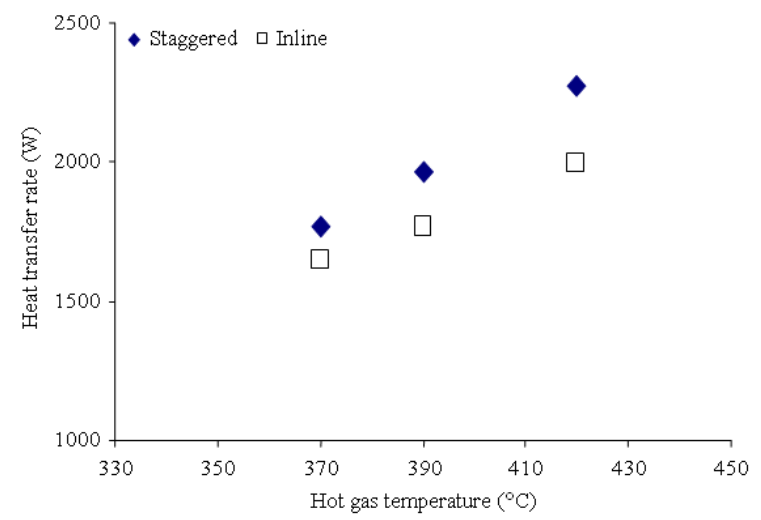

Fig. 8: The effect of tube arrangement on the heat transfer rate

Figure 7 compares the internal diameter with the heat transfer rate. When the internal diameter changed from 0.013-0.020 $\mathrm{m}$, the heat transfer rate increased from 2065.1-2273.6 W. For both arrangements, the experimental results of the heat transfer rate were similar.

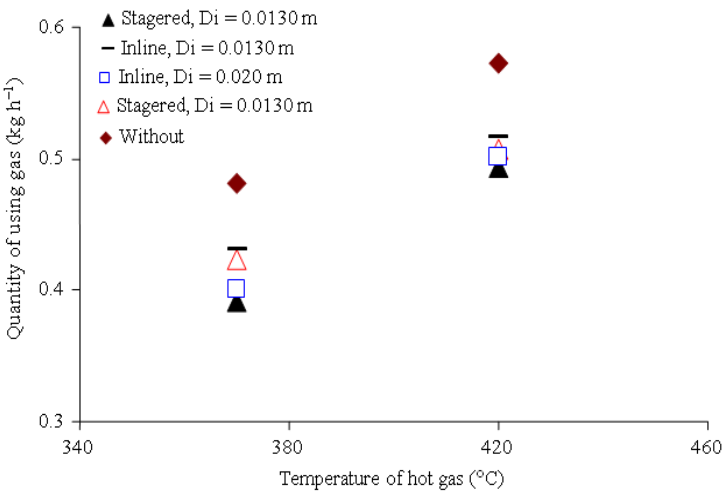

Fig. 9: Installed and without heat pipe air-preheater

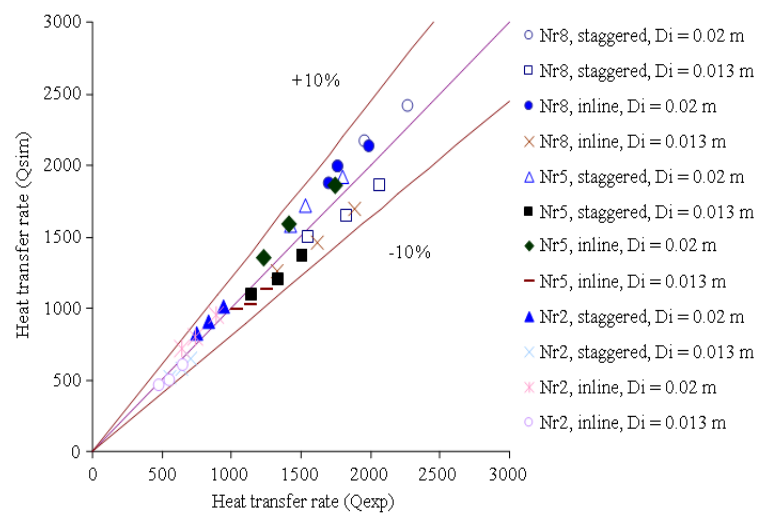

Fig. 10: Comparison of the heat transfer rate between the simulation model and the experimental results

The highest heat transfer was attained at the maximum internal diameter of $0.020 \mathrm{~m}$. This is because a smaller internal diameter leads to an increased frictional pressure drop and flow resistance. It can be concluded that when the internal diameter increase, the heat transfer rate will increase.

Effect of tube arrangement on the heat transfer rate: In this experiment, the effect was measured for the heat pipe air-preheater with eight rows and six columns when the hot gas temperature was $420^{\circ} \mathrm{C}$ with the mass flow rate of $0.0098 \mathrm{~kg} \mathrm{sec}^{-1}$ and the internal diameter of $0.020 \mathrm{~m}$. Figure 8 compares the tube arrangement with the heat transfer. It was found that when the tube arrangement changed from inline to staggered arrangement, the heat transfer increased from 1996.6-2273.6 W. This is because the staggered arrangement had frontal area of heat pipe for connecting hot gas flow more than inline arrangement. Thus, the hot gas outlet air temperature increased and 
temperature difference between the inlet and outlet hot gas also increased and the heat transfer rate was high. It can be concluded that when the tube arrangement changed from inline to staggered arrangement, the heat transfer increased.

\section{DISCUSSION}

The comparison between installed heat pipe airpreheater and without heat pipe air-preheater on quantity of gas, Fig. 9 shows the comparison heat pipe air-preheater on quantity of using gas for the waste heat recovery by heat pipe air-preheater from the furnace in a hot forging process. It indicated that when installed the heat pipe air-preheater, the quantity of using gas will decrease. And when the tube arrangement changed from staggered to inline arrangement, the quantity of using gas will increase. Figure 10 compares the heat transfer rate experimental data with the predicted heat transfer rate from the mathematical model. The prediction compared well with the experimental data. It can be concluded that when the hot gas temperature increased, the heat transfer rate also increased. The experimental data is in the standard deviation of $\pm 10 \%$ from the mathematical models.

\section{CONCLUSION}

This research designed and built the experimental prototype to investigate the applicability of the heat pipe air-preheater as a waste heat recovery device for a hot brass forging process. The major conclusions were follows as:

- The quantity of using gas for waste heat recovery by heat pipe air-preheater, when installed the heat pipe air-preheater was lower than the without heat pipe air-preheater

- When the hot gas temperature increased, the heat transfer rate also increased

- When the internal diameter increased, the heat transfer rate increased

- The heat pipe air-preheater can reduced the quantity of using gas and achieved energy thrift

- The mathematical models could be used to predict the heat transfer of the heat pipe air-preheater in a hot brass forging process. The results agreed well with those of experiment

\section{ACKNOWLEDGEMENT}

The research has been supported generously by SCG (Thailand). Co, Ltd and Faculty of Engineering,
Mahasarakham University for all the support provided. The authors express their since appreciation for all of the support provided.

\section{REFERENCES}

Engineering Data Science Unit No. 80017, 1980. Thermophysical Properties of Heat Pipe Working Fluid: Operating range between-60 and $300^{\circ} \mathrm{C}$, ESDU International Publishing, London, UK, ISBN: 978-0-85679-300-4.

Hewitt, G.F., G.L. Shires and T.R. Bott, 1994. Process Heat Transfer. CRC Press, ISBN: 1567001491.

Lukitobudi, A., A. Akbarzadeh, P. W. Johnson and P. Hendy, 1995. Design, construction and testing of a thermosyphon heat exchanger for medium temperature heat recovery in bakeries. Heat Recovery Syst., 15: 481-491. DOI: 10.1016/08904332(95)90057-8

Noie-Baghban, S.H. and G.R. Majideian, 2000. Waste heat recovery using Heat Pipe Heat Exchanger (HPHE) for surgery rooms in hospital. Applied Thermal Eng., 20: 1271-1282. DOI: 10.1016/S1359-4311(99)00092-7

Nuntaphan, A. and T. Kiatsiriroat, 2004. Performance of thermosphon heat exchanger modified from automobile radiator. Proceeding of the 18th Conference of Mechanical Engineering Network of Thailand, Oct. 18-20, Khon Kean, Thailand, pp: 1-8. http://www.me.psu.ac.th/tsme/ME_NETT18/fullpa per/tsf/TSF08.pdf

Payakaruk, T., P. Terdtoon and S. Ritthidech, 2000. Correlations to predict heat transfer characteristics of inclined closed two phase thermosyphon at normal operating heat pipe at normal operating condition. Applied Thermal Eng., 20: 781-790. DOI: 10.1016/S1359-4311(99)00047-2

Wangnipparnto, S., J. Tiansuwan, T. Kiatsiriroat and C.C. Wang, 2003. Performance analysis of thermosyphon heat exchanger under electric field. Energy Convers. Manage., 44: 1163-1175. DOI: 10.1016/S0196-8904(02)00104-8

Wu, X.P., P. Johnson and A. Akbarzadech, 1997. Application of heat pipe heat exchangers to humidity control in air-conditioning systems. Applied Thermal Eng., 17: 561-568. DOI: 10.1177/0143624408091026

Zukauskas, A., 1987. Heat Transfer from Tubes in Cross Flow. In: Advanced in Heat Transfer, Hartnett, J.P. and T.F. Irvine (Eds.). Academic Press, New York, ISBN: 0-12-020018-X, pp: 87-157. 